\title{
Multimedia Appendix
}

Table 1 Foods included in the validated Food Frequency Questionnaire (FFQ) for Morocco

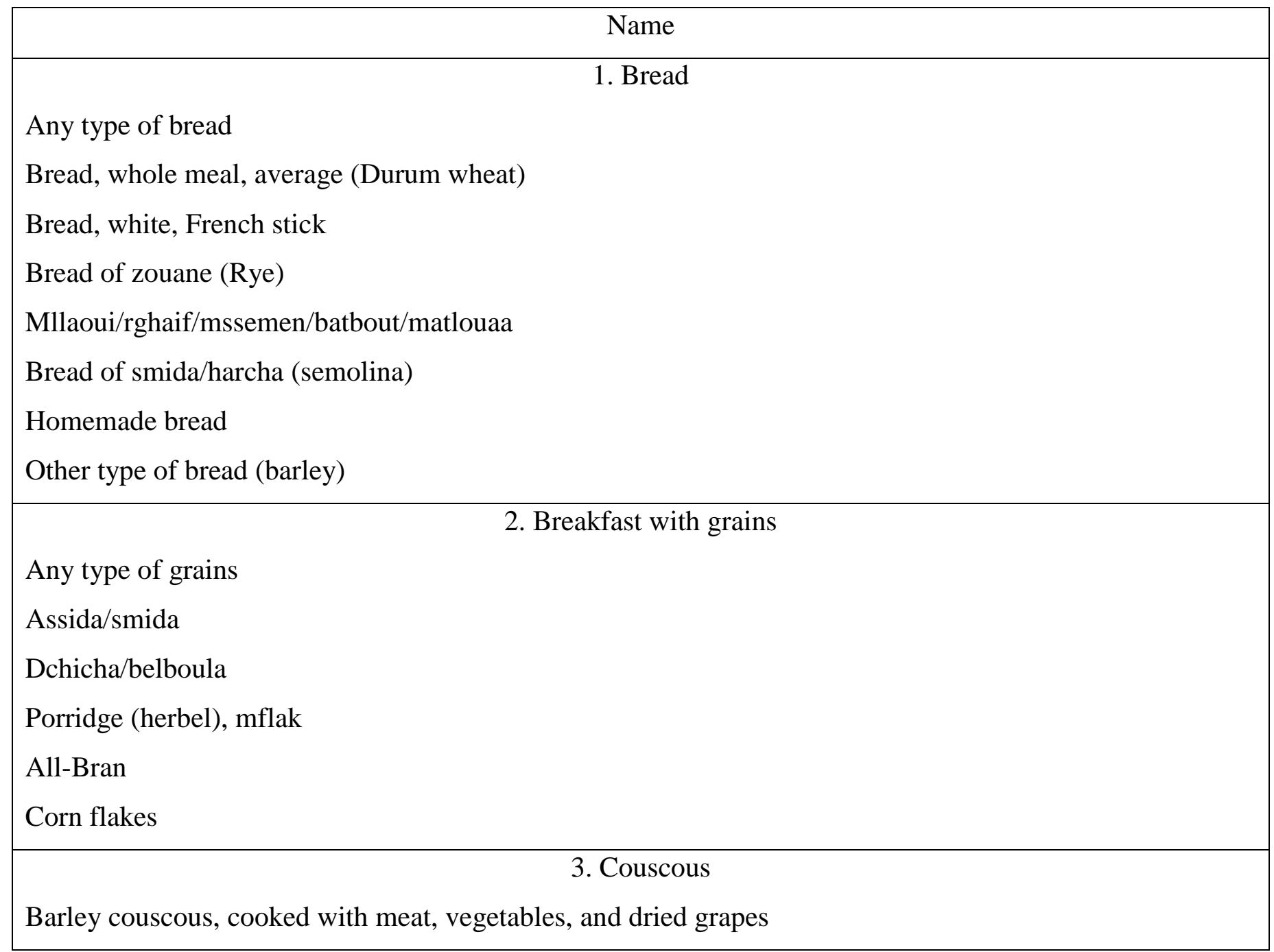


Barley couscous, cooked with sugar and cinnamon

Wheat couscous, cooked with meat, vegetables, and dried grapes

Wheat couscous, cooked with sugar and cinnamon

Corn couscous, cooked with meat, vegetables, and dried grapes

Corn couscous, cooked with sugar and cinnamon

4. Pasta

Any type of pasta

Pasta white boiled (spaghetti, macaroni)

Pasta, whole meal, boiled

Pasta with meat, vegetables, and cheese

Chaaria Mhammsa

5. Cake

Any type of cake, cherry

Madeleine cake

Cake with dates

Croissants

Moroccan sweets

Basboussa Maqrout

Aassida

Doughnuts, ring

Rice pudding, canned 


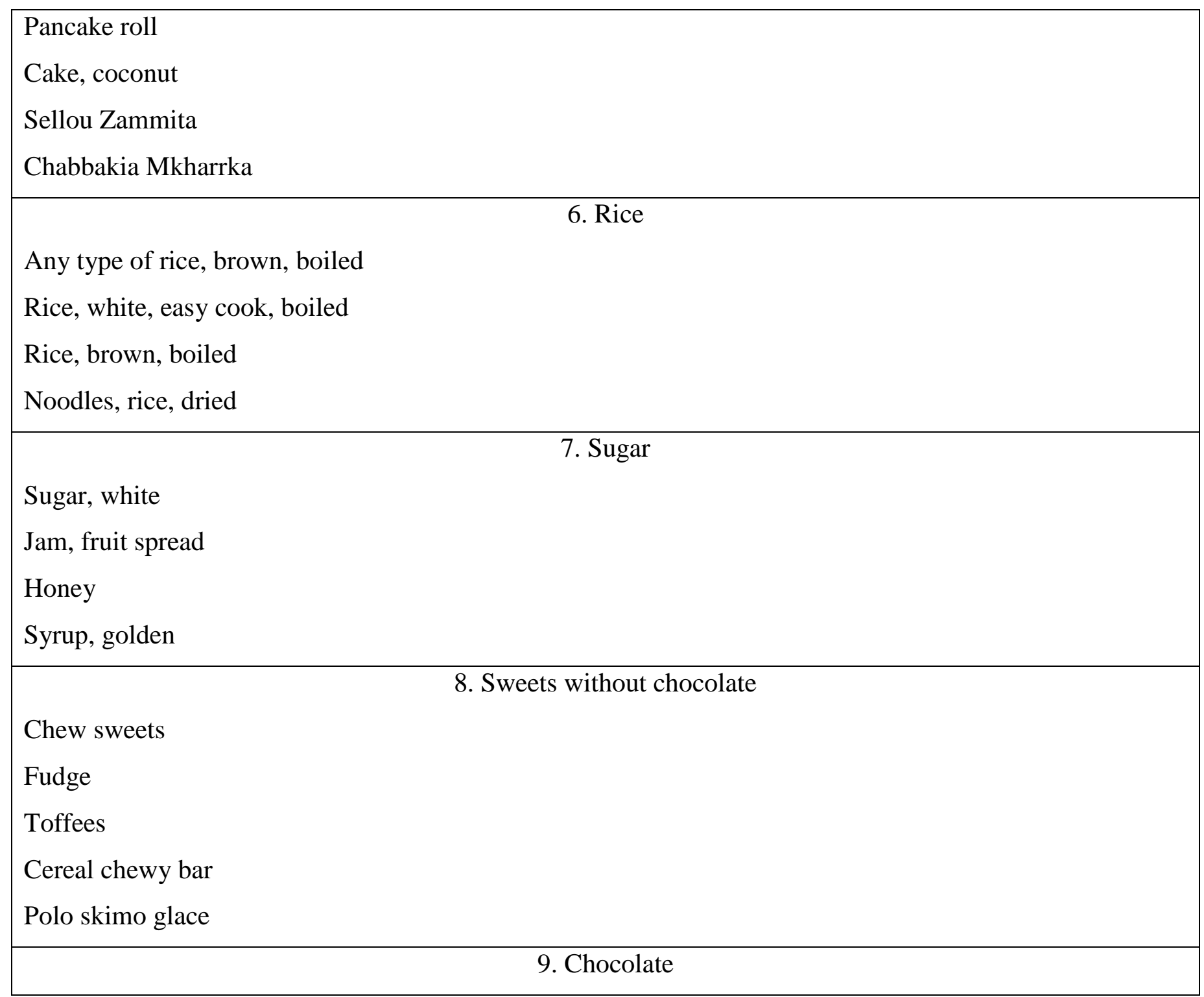




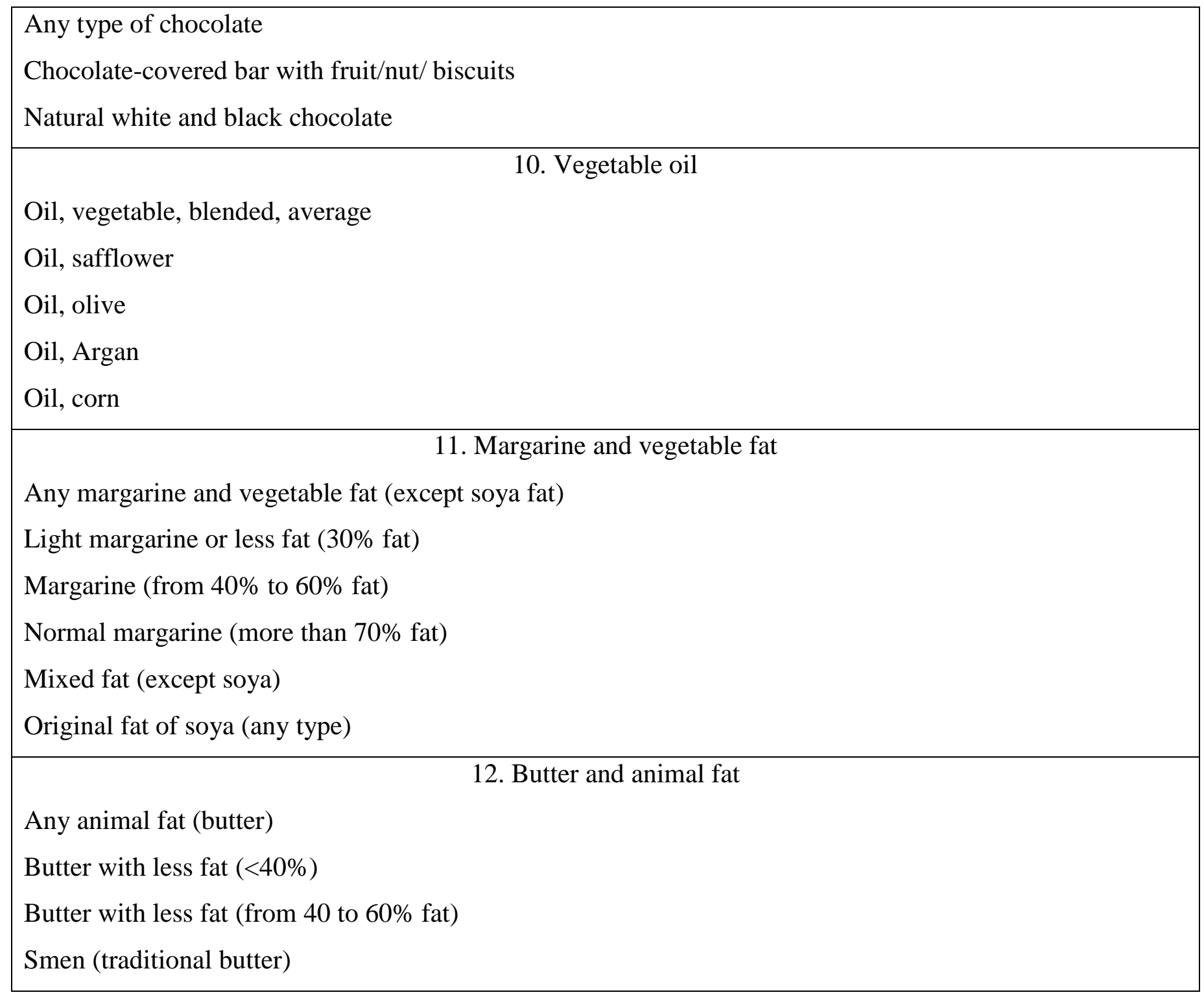




\section{Nuts}

\section{Any type of dried Fruit}

Peanuts, plain

Cashew nuts, roasted and salted

Almonds, roasted

Walnuts

Pistachio nuts, roasted and salted

Chestnuts

Oak nut

Any legumes

White beans, boiled

Lentils, red, split, boiled

Chick peas, whole, dried, boiled unsalted

Green beans/French beans, raw

Broad beans, frozen, boiled in unsalted

Soya beans, dried, boiled

Peas, raw

Any vegetables except potatoes

Lettuce, average, raw 


Spinach, raw
Fenugreek seeds
Rejla; Bakkoula
Mloukhia (Jews Mallow)
Tomatoes, raw
Aubergine, raw (Eggplant)
Courgette, raw (squash)
Peppers, red, raw, yellow
Cucumber, raw
Carrots, raw
Parsnip, raw
Swede, raw
Artichoke globe, raw
Radish, white, mooli, raw
Beetroot, raw
Chili peppers, green, raw
Sweet corn kernels, raw
Asparagus, raw
Aromatic herbs (mint basilica, parsley basil coriander)
Mushrooms, black, white


Onions, raw

Garlic, raw

Cauliflower, raw

Pumpkin red

Brussels sprouts, raw

Broccoli, green, raw

Cabbage white, red, green

Tomatoes stuffed with vegetables

Pickle, mixed veg

Ginger, root

16. Potatoes (mean dish)

Any type of potatoes

Potatoes, old mashed with hard margarine

Potatoes, old, baked, flesh and skin

Chips, homemade, fried in blended oil

Salad, potato with French dressing

Potato cakes fried in vegetable oil

Tortillas

Sweet potato

17. Fruits (one unit)

Any type of fruits 


\begin{tabular}{|l|}
\hline Apples \\
Pears \\
Bananas \\
Peaches \\
Avocado \\
Cherries \\
Lemon pickles \\
Mulberries, raw, blackcurrants, raspberries \\
Watermelon \\
Grapes \\
Mangoes \\
Apricots \\
Nectarines \\
Plums \\
Dried mixed fruit \\
Pineapple \\
Kiwi fruit \\
Juice, lemon \\
Oranges \\
Mandarin \\
Grapefruit \\
\hline
\end{tabular}




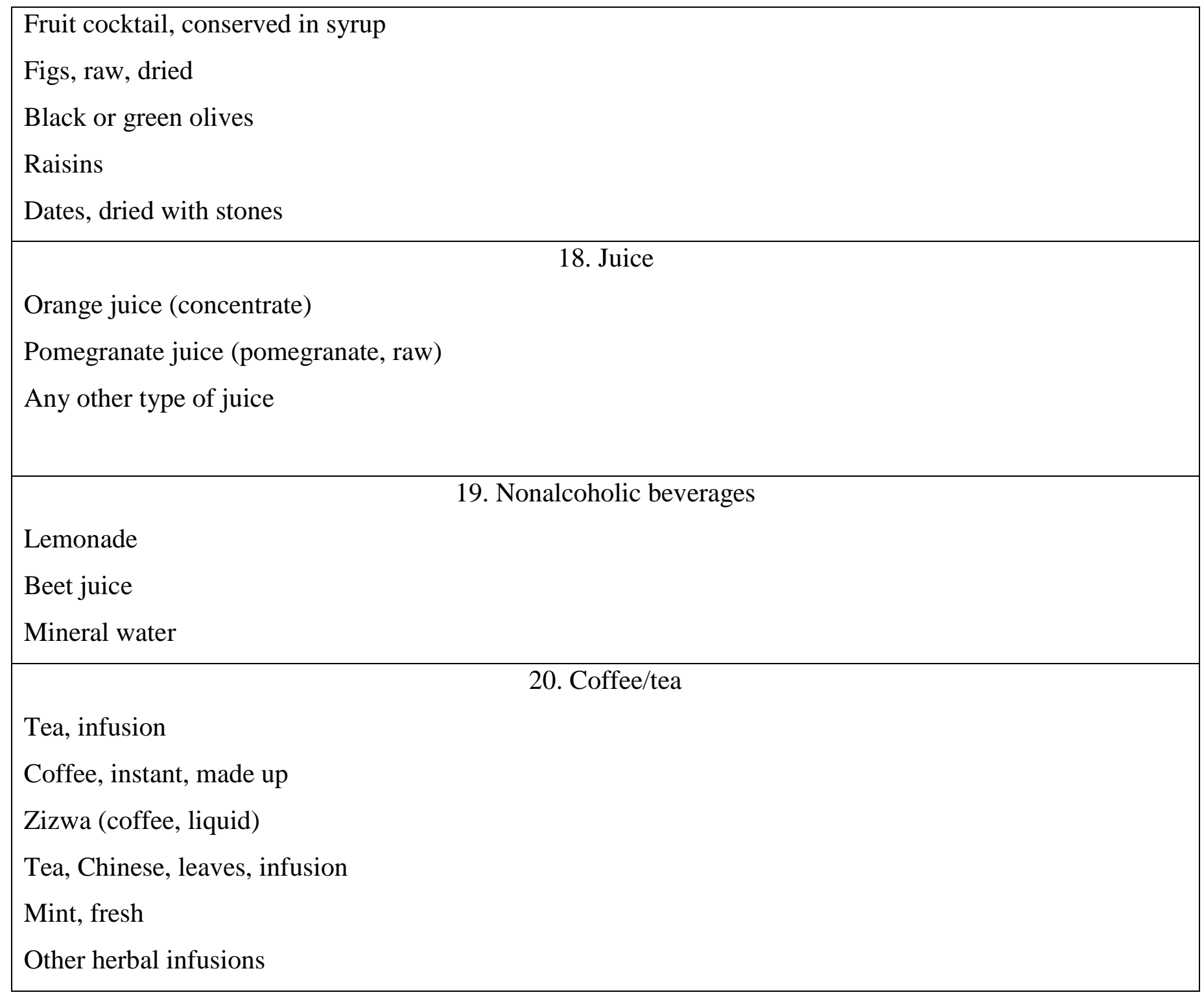




\section{Beer}

Any type of beer

22. Wine

Any type of wine

Wine, red

Wine, white, dry

Wine, rose

23. Other alcoholic beverages

Port, sherry, liqueur,

Spirits $37.5 \%$

24. Red meat

Any type of red meat (beef, cow, lamb, goat)

Beef, fillet steak, forerib, lean \& fat, roast, steamed, grilled

Beef in tagine

Minced meat of beef

Lamb, grilled, steamed, roasted

Lamb cooked in tagine, mrouzia

Minced meat of lamb

Goat meat

Veal, fillet, roast

Camel meat 


\begin{tabular}{|l|}
\hline Rabbit, duck, partridge \\
Sausage of beef, lamb, cow, chilled, fried \\
Kocha or bread filled with meat \\
Kabab, shawarma \\
Pork \\
Khliaa/dried meat \\
Khliaa (dried meat with salt and cooked with fat), cow \\
Khliaa (dried meat with salt and cooked with fat), sheep \\
Qaddid (dried meat with salt), cow, sheep \\
Dried pork meat \\
\hline Any type of chicken \\
Chicken steamed \\
Chicken cooked in tagine \\
Chicken grilled and roasted \\
Turkey steamed \\
Turkey cooked in tagine \\
Turkey grilled and roasted \\
Sausage and skewer of turkey \\
Poultry smoked, conserved \\
Any poultry smoked, conserved (eg, mortadella and casheer) \\
\hline
\end{tabular}




\section{Offal (sekat)}

Liver of beef, lamb

Tongue, heart, kidney, head, brain, of cow or beef or sheep, lamb

27. Fish

Any fish fresh, smoked, white, fat

Fresh fat fish (eg, salmon, tuna, truite, sardine, and bouri)

White fresh fish (eg, sole and merlan)

Fresh fish/other sea foods (eggs of fish)

Seafood shrimp, squid, mussels

Frozen seafood

Frozen fat fish (eg, salmon, tuna, truite, sardine, and bouri)

Frozen white fish (eg, sole and merlan)

Conserved fat fish (eg, salmon, tuna, truite, sardine, and bouri)

Fat fish dried or smoked (eg, salmon, tuna, truite, sardine, and bouri)

White fish dried or smoked (eg, sole and merlan)

Conserved seafood shrimp, squid, and mussels

$$
\text { 28. Eggs }
$$

Farmer eggs

Farmer egg boiled or sandwich

Farmer eggs' meals: omelet, eggs with tomatoes, eggs with pepper and tomatoes

Dessert with farmer eggs (cake, egg tart) 


Industrial eggs
Industrial egg boiled or sandwich
Industrial eggs' meals: omelet, eggs with tomatoes, eggs with pepper and tomatoes
Dessert with industrial eggs (cake, egg tart)
Whole milk (milk, cow, whole, 3.5\% fat)
Lben (alone or with fruit)
Skimmed milk (milk, cow, skimmed, 0.5\% fat)
Semi skimmed milk (milk, cow, partly skimmed, $1.5 \%$ fat)
Milk free fat
Raib
Soya milk
Saykook
Yogurt
Yogurt Activia
Soya yogurt
Any type of cheese
Hard cheese (eg, cheddar and parmesan)
Soft cheese (camembert, brie, Philadelphia)
So. Cheese




\begin{tabular}{|l|}
\hline Jben (natural or aromatic) \\
Fresh cheese (eg, vita, mozzarella) \\
Others: La vache qui rit, Kiri, Coeur du lait, Junior \\
\hline Ice cream \\
Cream \\
Fresh cream \\
Double cream \\
\hline Soup with vegetables and meat \\
Soup with vegetables and grains (eg, Dchicha and Smida) \\
Soup with meat or offal \\
Soup with fish \\
Tagine with meat or poultry \\
Salt brick \\
Pizza \\
Sorghum \\
Chili sauce \\
Ketchup \\
Salad sauce \\
Mayonnaise
\end{tabular}


Mustard 